- Nhiễm khuẩn nặng làm tăng nguy cơ tổn thương thận 2,1 lần (OR 2,1; $p<0,05)$.

- Bệnh nhân nhiễm khuẩn nặng có tổn thương thận cấp tử vong rất cao $61,6 \%$, nguy cơ tử vong gấp 4,7 lần so với nhóm không có tổn thương thận (OR 4,7; $(p<0,001)$.

- Những bệnh nhân phải lọc máu tỉ lệ tử vong lên tới $75 \%$, nguy cơ tử vong gấp 21 lần so với những bệnh nhân không phải lọc máu (OR 21; $\mathrm{p}<0,001$ ).

- Bênh nhân xuất hiện tổn thương thận muộn sau khi vào viện tử vong cao nhất $(80 \%)$, $p<0,01$ : thường trong tình trạng bệnh nặng, suy đa tạng, nguy cơ tử vong gấp 8 lần so với nhóm tổn thương mức độ nhẹ khi vào viện (OR 8,0; $\mathrm{p}<0,001)$.

\section{TÀI LIẸU THAM KHẢO}

1. Bagshaw, S. M., et al. (2007). "Septic acute kidney injury in critically ill patients: clinical characteristics and outcomes". Clin J Am Soc Nephrol 2(3): 431-439.

2. Bellomo R., Ronco C., Kellum J A. (2004). "Acute renal failure - definition, outcome measures, animal models, fluid therapy and information technology needs: the Second International Consensus Conference of the Acute Dialysis Quality Initiative (ADQI) Group". Critical Care, 8(20, 204-212.

3. Dellinger, R. P., et al. (2013). "Surviving Sepsis Campaign: international guidelines for management of severe sepsis and septic shock, 2012". Intensive Care Med 39(2): 165-228.

4. De Mendonca A., Vincent J.L. et al. (2000). "Acute renal failure in the ICU: risk factors and outcome evaluated by the SOFA score". Intensive Care Med 26(7): 915-921.

5. Metnitz, P. G., et al. (2002). "Effect of acute renal failure requiring renal replacement therapy on outcome in critically ill patients". Crit Care Med 30(9): 2051-2058

6. Piccinni, P., et al. (2011). "Prospective multicenter study on epidemiology of acute kidney injury in the ICU: a critical care nephrology Italian collaborative effort (NEFROINT)". Minerva Anestesiol 77(11): 1072-1083.

7. Schrier R. W. and W. Wang (2004). "Acute renal failure and sepsis". N Engl J Med 351(2): 159-169.

8. Uchino, S., et al. (2005). "Acute renal failure in critically ill patients: a multinational, multicenter study". Jama 294(7): 813-818.

9. Singer M., et al. (2016). "The third international consensus definitions for sepsis and septic shock (sepsis-3)." JAMA 315(8): 801-810.

\title{
KHẢO SÁT NGUYÊN NHÂN GÂY KHIẾM THỊ Ở NGƯờI VIỆT NAM
}

\section{Nguyễn Thị Thu Hiền ${ }^{1}$, Trần Phương Anh ${ }^{1}$, Phạm Thị Minh Châu ${ }^{1}$}

\section{TÓM TẮT}

Mục tiêu: Khảo sát nquyên nhân gây khiếm thi ở người Việt Nam. Đối tướng: Nghiên cứu được thực hiện trên 886 người khiếm thị đến khám tại Phòng phuc hồi chức năng khiếm thi của Bênh viên Mắt Trung ươna trona 3 năm từ 2013 đến 2016. Phương pháp nghiên cứu: mô tả cắt ngang. Kết quả: trên 886 đối tượng gồm: 515 nam và 371 nữ, trong đó trẻ em là 478 (tuổi trung bình $9.23 \pm 3.2$ ) và người lớn là 408 (tuổi trung bình $29.71 \pm 14.1$ ). Các nhóm bệnh gây khiếm thị thường gặp gồm: bệnh lý võng mạc $27.2 \%$ (thoái hóa sắc tố võng mạc 46.4\%; bệnh võng mac trẻ đẻ non $15.8 \%$; thoái hóa hoàng điểm $14.5 \% \ldots$ ), bệnh lý thể thủy tinh $24.3 \%$ (đã lấy thể thủy tinh $4 \dot{4} .2 \%$, đã đăt thể thủy tinh nhân tao $40 \%$...), nhóm tật khúc xạ chiếm $16.7 \%$ (cận thị $63.5 \% \ldots)$. Tuy nhiên, giữa hai đối tương trẻ em và người lớn tỷ lệ phân bố các nguyên nhẩn không giống nhau: ở trẻ em nhóm bệnh lý võng mạc chiếm tỷ lế cao nhất (28.2\%); nhóm tât khúc xa đứng thứ hai (20.5\%); nhóm bệnh lý thể thủy tinh đứng thứ ba

${ }^{1}$ Bệnh viện Mắt Trung Ương

Chịu trách nhiệm chính: Nguyễn Thị Thu Hiền

Email: thuhienvnio@gmail.com

Ngày nhận bài: 16.12.2020

Ngày phản biên khoa hoc: 22.01.2021

Ngày duyệt bài: 8.2 .2021
(19.9\%); còn ở người lớn nhóm bệnh lý thể thủy tinh chiếm tỷ lệ cao nhất (29.4\%); nhóm bênh lý võng mac đứng thứ hai $(26.0 \%)$; nhóm tật khúc xa và nhóm bênh lý thi thần kinh đứng thứ ba $(12.3 \%)$. Kết luận: Nguyên nhân gây khiếm thị ở người Việt Nam đứng thứ nhất là do bênh lý võng mac, đứng thứ hai là bệnh lý thể thủy tinh và đứng thứ ba là tật khúc xạ.

Từ khóa: nguyên nhân, khiếm thị.

\section{SUMMARY SURVEYING THE CAUSES OF LOW VISION IN VIETNAM}

Obiective: To survey the causes of low vision in Vietnam. Research methods: cross-section study with 886 patients (515 males, 371 females) participated from 2013 to 2016 in low vision unit in Vietnam National Eye Hospital, there were 478 children (mean age $9.23 \pm 3.2$ years old) and 408 adults (mean age $29.71 \pm 14.1$ years old). Results: Causes of low vision included retinal diseases $27.2 \%$ (retinitis pigmentosa $46.4 \%$, retinopathy of prematurity $15.8 \%$, macular degeneration $14.5 \% \ldots$ ), lens-related disorders $24.3 \%$ (after cataract surgery: aphakia $44.2 \%$, intraocular lens implants $40 \% \ldots$, refractive errors $16.7 \%$ (by myopia $63.5 \% \ldots$...). However, there was a different contribution of low vision causes between children and adults. In children ( $\leq 15 y \mathrm{rs}$ ), the leading causes were retinal diseases $28.2 \%$, then refractive errors $20.5 \%$, lens-related 
disorders $19.9 \%$. But in adults (>15 yrs), lens diseases were the first rank at $29.4 \%$, retinal diseases were the second at $26 \%$, then refractive errors and optic nerve disease were $12.3 \%$. Conclusion: The most common causes of low vision in Vietnamese patients were retinal diseases, lens-related disorders, refractive errors.

Key words; cause, low vision.

\section{I. ĐẶT VẤN ĐỀ}

Người khiếm thị là người mà khả năng nhìn còn lại rất kém, tổn thương thị giác gây cản trở việc thực hiện các công việc hàng ngày, điều này có thể gây tác động không tốt đến cuộc sống xã hội và kinh tế của họ. Tổ chức y tế thế giới (WHO) năm 1992 đã đưa ra khái niệm khiếm thị dùng trong thực hành lâm sàng: một người được goi là khiếm thị khi chức năng thị giác của người đó bị giảm nặng, thậm chí ngay cả khi đã được điều trị và điều chỉnh tật khúc xa tốt nhất nhưng thị lực ở mắt tốt chỉ ở mức dưới $6 / 18(0,33)$ cho đến còn phân biệt sáng tối (ST+) và/hoặc thị trường bị thu hẹp dưới $10^{\circ}$ kể từ điểm định thị.

Nhiều nguyền nhân tại mắt và toàn thân có thể gây khiếm thị. Trên một người khiếm thị có thể có một hoặc nhiều nguyên nhân đồng thời phối hợp. Có nhiều cách phân loại nguyên nhân gây khiếm thị: phân loại theo tổn thương giải phấu, phân loại theo bệnh học, phân loại theo tổn thương chức năng thị giác... Từ việc tìm hiểu nguyên nhân gây khiếm thị giúp cho các bác sỹ nhãn khoa đề ra chiến lược và các phương pháp phục hồi chức năng thích hợp nhằm hỗ trợ cho người khiếm thị sử dụng tối ưu phần thị giác còn lại trong cuộc sống.

Trên thế giới, ở những nước phát triển, xã hội rất quan tâm đến những người khuyết tật trong đó có người khiếm thị. Tại Mỹ hiện nay, người khiếm thị lớn tuổi đang là một vấn đề thời sự bởi số lượng người khiếm thị do bệnh thoái hoá hoàng điểm tuổi già ngày càng gia tăng.

ở Việt Nam, từ năm 1999, lînh vực khiếm thị mới bắt đầu được quan tâm, từ đó đến nay những nghiên cứu trong lĩnh vực này chủ yếu tập trung vào đánh giá về chức năng thị giác và hiệu quả của các phương pháp trợ thị, chưa có nghiên cứu nào đi sâu tìm hiểu cụ thể về nguyên nhân gây khiếm thị, vì vậy chúng tôi nghiên cứu đề tài này nhằm mục tiêu: "Khảo sát nguyên nhân gây khiếm thị ở người Việt Nam".

\section{II. ĐỐI TƯợNG VÀ PHƯƠNG PHÁP NGHIÊN CỨU}

Nghiên cứu được thực hiện trên 886 đối tượng khiếm thị đển khám tại Phòng phục hồi chức năng khiếm thị của Bênh viện Mắt Trung ương trong 3 năm từ 2013 đến 2016.
Tiêu chuẩn lựa chọn: Người được xác định là khiếm thị ở tất cả các lứa tuổi.

Tiêu chuấn loại trừ: Người khiếm thị đang mắc bệnh cấp tính hay tinh thần không ổn định

Thiêt kế nghiên cứu: nghiên cứu mô tả cắt ngang

Cớ mẫu: Thu thập số liệu của toàn bộ người khiếm thị đến khám trong thời gian nghiên cứu (tổng số 886 người khiếm thi)

Phương tiện khám: máy sinh hiển vi khám bệnh, máy soi đáy mắt, máy soi bóng đồng tử, các phương tiện chẩn đoán hình ảnh phối hợp...

Các bước tiến hành: hỏi bệnh sử, hỏi tiền sử, khám mắt chẩn đoán nguyên nhân.

Thu thập số liệu và xử lý số liệu bằng phần mềm SPSS

\section{KẾT QUẢ NGHIÊN CỨU VÀ BÀN LUÂN}

3.1. Đắc điểm nhóm nghiên cứu. Trong 886 đối tượng có 515 nam và 371 nữ. Trong đó nhóm đối tượng trẻ em từ 15 tuổi trở xuống (theo định nghĩa của WHO về quyền trẻ em) là 478 và nhóm người lớn từ 16 tuổi trở lên là 408.

\section{Bảng 1: Phân bố theo tuổi}

\begin{tabular}{|c|c|c|c|}
\hline \multicolumn{2}{|c|}{ Nhóm tuối } & Số người (n) & Tỷ lệ (\%) \\
\hline \multirow{3}{*}{ Trẻ em em } & $<6$ tuối & 62 & 7 \\
\cline { 2 - 4 } & $6-10$ tuổi & 232 & 26.2 \\
\cline { 2 - 4 } & $11-15$ tuối & 184 & 20.8 \\
\hline \multirow{2}{*}{$\begin{array}{c}\text { Người } \\
\text { lớn }\end{array}$} & $16-40$ tuối & 342 & 38.6 \\
\cline { 2 - 4 } & $41-60$ & 41 & 4.6 \\
\cline { 2 - 4 } & $>60$ & 25 & 2.8 \\
\hline
\end{tabular}

Nhóm trẻ em tuối trung bình $9.23 \pm 3.2$ tuối (đối tượng nhỏ tuổi nhất là 3 tuổi). Nhóm người lớn tuổi trung bình $29.71 \pm 14.1$ tuổi (tuổi cao nhất là 89 tuổi).

3.2. Nguyên nhân gây khiếm thị ở người Việt nam. Nguyên nhân gây khiếm thị phân loại theo bệnh học, được chia thành các nhóm sau đây.

Trong các nguyên nhân gây khiếm thị, nhóm bệnh lý võng mạc chiếm tỷ lệ cao nhất $27.2 \%$; đứng thứ hai là nhóm bệnh lý thể thủy tinh $24.3 \%$; đứng thứ ba là nhóm tât khúc xa $16.7 \%$; tiếp đến là các nhóm rung giật nhãn cầu $12.9 \%$; nhóm liên quan bệnh lý thị thần kinh $10.5 \%$... Tuy nhiên, giữa hai đối tượng trẻ em và người lớn tỷ lệ phân bố các nguyền nhân không giống nhau: ở trẻ em nhóm bệnh lý võng mạc chiếm tỷ lệ cao nhất (28.2\%); nhóm tật khúc xạ đứng thứ hai $(20.5 \%)$; nhóm bênh lý thể thủy tinh đứng thứ ba $(19.9 \%)$; còn ở người lớn nhóm bệnh lý thể thủy tinh chiếm tỷ lệ cao nhất $(29.4 \%)$; nhóm bệnh lý võng mạc đứng thứ hai $(26.0 \%)$; nhóm tật khúc xạ và nhóm bệnh lý thị thần kinh đứng thứ ba (12.3\%). 


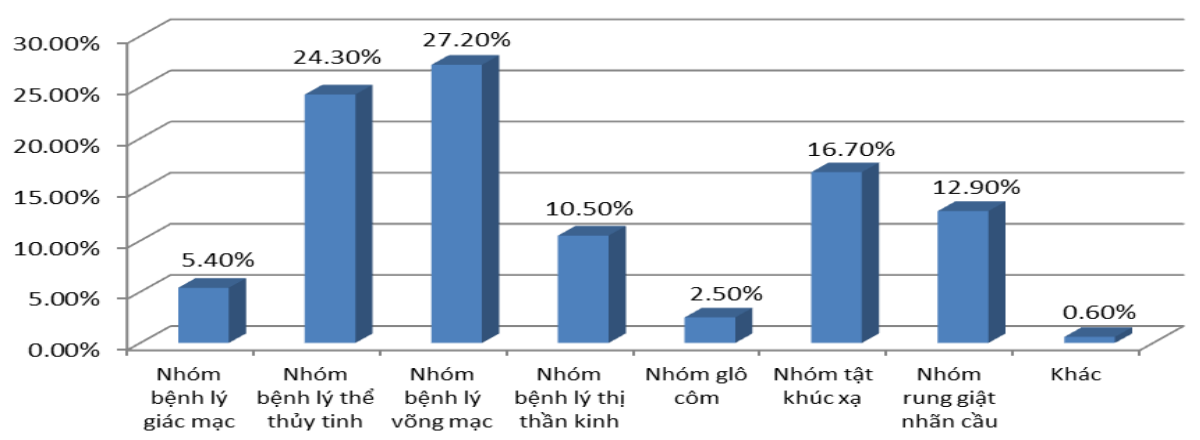

Biểu đồ 1: Phân loại nguyên nhân gây khiếm thị theo bệnh học

Nguyên nhân gây khiếm thị trên trẻ em so với các báo cáo trước đây có xu hướng thay đổi: trong nghiên cứu trên 107 trẻ từ 5-16 tuổi của N.T.T. Hiền năm 2007 thấy nguyên nhân chiếm tỳ lệ cao nhất là nhóm bệnh lý thể thủy tinh $(51 \%)$, tiếp đến là nhóm tật khúc xạ và bệnh lý võng mạc thị thần kinh. Nguyên nhân gây khiếm thị trên người lớn so với các báo cáo trước đây xu hướng không thay đổi: trong nghiên cứu trên 167 người khiếm thị trên 18 tuổi của N.T.T.Hiền năm 2014 thấy nguyên nhân chiếm tỷ lệ cao nhất là nhóm bệnh lý thể thủy tinh (34.1\%\%); tiếp đến là nhóm bệnh lý võng mạc hoàng điểm $(23.2 \%)$ và nhóm bệnh lý thị thần kinh $(14.4 \%)$.

Kết quả của chúng tôi khác với các báo cáo tại Viện Mắt Nepal: nguyên nhân hàng đầu gây khiếm thị là rung giật nhãn cầu (30.7\%), tật khúc xạ cao không được chỉnh kính (22.6\%), các nguyên nhân thường gặp tiếp theo là đục thể thủy tinh $(15.3 \%)$, thoái hóa sắc tố võng mạc (15.3\%),thoái hóa hoàng điểm tuổi già (13.1\%). Nghiên cứu tại nam Ấn Độ cho thãy tật khúc xạ là nguyên nhần chính gây khiếm thị $(68 \%)$ còn lại là bệnh lý đục thể thủy tinh (22\%).

Bảng 2: Nguyên nhân khiếm thị do bệnh lý vông mạc

\begin{tabular}{|c|c|c|c|c|c|c|}
\hline Nhóm bệnh & \multicolumn{2}{|c|}{ Tré em } & \multicolumn{2}{c|}{ Ngưỡ lớn } & \multicolumn{2}{c|}{ Tống } \\
\hline Thoái hóa sắc tố VM & 44 & $33.3 \%$ & 65 & $63.7 \%$ & 109 & $46.4 \%$ \\
\hline Bong VM & 6 & $4.5 \%$ & 7 & $6.9 \%$ & 13 & $5.4 \%$ \\
\hline Khuyết VM & 8 & $6.1 \%$ & 2 & $2.0 \%$ & 10 & $4.1 \%$ \\
\hline ROP & 36 & $27.3 \%$ & 2 & $2.0 \%$ & 38 & $15.8 \%$ \\
\hline Sẹo, teo VM & 11 & $8.3 \%$ & 6 & $5.9 \%$ & 17 & $7 \%$ \\
\hline Thoái hóa HĐ & 18 & $13.6 \%$ & 17 & $16.7 \%$ & 35 & $14.5 \%$ \\
\hline Khác & 3 & $2.2 \%$ & 4 & $3.8 \%$ & 7 & $2.9 \%$ \\
\hline
\end{tabular}

Nhóm nguyên nhân gây khiếm thị do bệnh lý võng mạc gặp nhiều nhất. Trong đó thoái hoác sắc tố võng mạc chiếm tỷ lệ cao nhất (46.4\%), tiếp đến bệnh võng mạc trẻ đẻ non (15.8\%), thoái hóa hoàng điểm (14.5\%). Tuy nhiên, tỷ lệ giữa các nhóm không hoàn toàn giống nhau giữa trẻ em và người lớn: ở trẻ em thường gặp nhất là bệnh thoái hóa sắc tố võng mạc $(33.3 \%)$, tiếp đến bệnh võng mạc trẻ đẻ non (27.3\%) và thoái hóa hoàng điểm $(13.6 \%)$; còn ở người lớn thường gặp nhất là bệnh thoái hóa sắc tố võng mạc $(63.7 \%)$, tiếp đến thoái hóa hoàng điểm $(16.7 \%)$. Bệnh thoái hóa sắc tố võng mạc là nhóm bệnh di truyền với dấu hiệu mù đêm xuất hiện từ nhỏ hoặc tuổi trưởng thành, gây tổn hại thị lực ban đêm, thu hẹp thị trường chu biên rồi dấn tới mất thị lực hoàn toàn. Chính vì vậy, bệnh lý này là nguyên nhân hàng đầu gây giảm thị lực trầm trọng gặp chủ yếu cả hai nhóm đối tượng trẻ em và người lớn $(p<0.01)$, người bệnh

thường đến ở giai đoạn rất muộn, thị lực giảm nặng và thị trường thu hẹp hình ống. Số lượng người khiếm thị do bệnh võng mac đái tháo đường và thoái hóa võng mạc tuổi già trong nghiên cứu của chúng tôi rất thấp, điều này có thể do các bác sỹ chuyên khoa về võng mạc vẫn đang theo dõi điêu trị hoặc chưa quan tâm đến việc phục hồi chức năng cho người khiếm thị do hai bệnh này nên chưa chuyển tuyến tới đơn vị phục hồi chức năng.

Nghiên cứu tại viện Mắt Thái Lan: bệnh lý võng mạc là nguyên nhân gây tổn hại thị lực chủ yếu. ở người trưởng thành, nhóm bệnh thường gặp là bệnh thoái hóa sắc tố võng mạc $(28.3 \%)$, tiếp theo là thoái hóa hoàng điểm tuổi già $(10.3 \%)$, glaucoma $(10.0 \%)$, bệnh võng mạc tiểu đường $(9.6 \%)$. Đối với trẻ nhỏ, bệnh lý mắt thường gặp nhất là tổn hại vỏ não thị giác $(17.7 \%)$, thiểu sản đĩa thị (13.4\%), bệnh lý võng mạc trẻ đẻ non (9.5\%). 
Bảng 3: Nhóm bệh lý thể thủy tinh

\begin{tabular}{|c|c|c|c|c|c|c|}
\hline Nhóm bệnh & \multicolumn{2}{|c|}{ Trẻ em } & \multicolumn{2}{c|}{ Người lớn } & \multicolumn{2}{c|}{ Tống } \\
\hline Đục TTT & 10 & $10.5 \%$ & 24 & $20 \%$ & 34 & $15.8 \%$ \\
\hline Đã lấy TIT & 40 & $42.1 \%$ & 55 & $45.8 \%$ & 95 & $44.2 \%$ \\
\hline Đã đặt IOL & 45 & $47.4 \%$ & 41 & $34.2 \%$ & 86 & $40 \%$ \\
\hline
\end{tabular}

Nhóm bệnh lý liên quan đến thể thủy tinh là nguyên nhân gây khiếm thị thứ hai thường gặp chiếm $24.3 \%$ (trẻ em $44.2 \%$ và người lớn $55.8 \%)$. Nhóm bệnh thể thủy tinh chủ yếu là tình trạng đã phẫu thuật lấy thể thủy tinh $44.2 \%$, đã đặt thể thủy tinh nhân tạo (IOL) $40 \%$, đục thể thủy tinh không được phẫu thuật $15.8 \%$.

Đục thể thủy tinh là tình trạng đục một phần hoặc toàn bộ thể thủy tinh gây cản trở ánh sáng vào võng mạc làm giảm thị lực. Phẫu thật lãy thể thủy tinh đắt thể thủy tinh nhân tao sẽ đem lai ánh sáng ở những người chỉ đục thể thủy tinh đơn thuần mà không kèm theo các bệnh mắt khác. Nhóm nghiên cứu của chúng tôi gặp nhóm chưa được phẫu thuật là $15.8 \%$ phần lớn do bệnh nhẩn được phát hiện muộn, hoặc phối hợp nguyên nhân khác như rung giật nhãn cầu, lác... hoặc phối hợp các bệnh khác không thể chỉ định phẫu thuật. Có sự khác biệt có ý nghĩa thông kê ở nhóm này trên cả 2 đối tượng trẻ em và người lớn $(p=0.043)$. Nhóm đã phẩu thuật và chưa đặt thể thủy tinh nhân tạo chiếm $44.2 \%$, tỷ lệ gẩn ngang nhau ở hai nhóm trẻ em và người lớn $(\mathrm{p}=0.342)$, ở nhóm này hay phối hợp di chứng treo đồng tử, rách võ bao sau trong phẫu thuật nên không đặt được thể thủy tinh nhân tạo. Có 40\% trường hợp đã phẫu thuật lẫy thể thủy tinh đục và đặt thể thủy tinh nhân tạo nhưng thị lực không tốt do đục thể thủy tinh bẩm sinh thường kèm rung giật nhãn cầu hoắc phẫu thuật quá muộn, sau phẫu thuật đặt thể thủy tinh nhân tạo găp các biến chứng như viêm màng bồ đào, lệch thể thủy tinh nhân tạo... Tỷ lệ đặt thể thủy tinh nhân tạo ở trẻ em đạt 47.4\%, cao hơn người lớn là $34.2 \%$, sự khác biệt có ý nghĩa thống kê với $\mathrm{p}=0.034$.

\section{Bảng 4: Nhóm khiếm thị do tật khúc xạ}

\begin{tabular}{|c|c|c|c|c|c|c|}
\hline Nhóm bệnh & \multicolumn{2}{|c|}{ Trẻ em } & \multicolumn{2}{c|}{ Người lớn } & \multicolumn{2}{c|}{ Tống } \\
\hline Cận thị & 64 & $65.3 \%$ & 30 & $60 \%$ & 94 & $63.5 \%$ \\
\hline Viền thị & 11 & $11.2 \%$ & 5 & $10 \%$ & 16 & $10.8 \%$ \\
\hline Loạn thị & 23 & $23.4 \%$ & 15 & $30 \%$ & 38 & $25.7 \%$ \\
\hline
\end{tabular}

Nhóm nguyên nhân do tật khúc xạ chiếm tỷ lệ cao thứ ba. ở cả nhóm trẻ em và người lớn tật cận thị chiếm tỷ lệ cao nhất. Tật cận thị không được phát hiện sớm, không được chỉnh kính phù hợp và cận thị thoái hóa hoặc cận thị đi kèm với loạn thị cao, rung giật nhãn câu là nguyên nhân chính chiếm tỷ lệ $63.5 \%$ (65.3\% ở trẻ em và $60 \%$ ở người lớn) dẫn đến suy giảm thị lực, thậm chí gây mù do các biến chứng của cận thị thoái hóa gây ra như: đục thể thủy tinh, bong võng mạc... Sự khác biệt theo từng phân nhóm nhỏ ở trẻ em và người lớn đều không có ý nghĩa thống kê với $p$ > 0.05.

Nhóm nguyên nhân rung giật nhãn cầu chiếm tỷ lệ 12.9\%; những đối tượng này được khám và phát hiện rung giật nhãn cầu bẩm sinh mà không kèm theo bệnh lý nào khác ở nhãn cầu.

Nhóm nguyên nhân gây khiếm thị liên quan bệnh lý thị thần kinh gồm nhóm bệnh khuyết gai thị, teo gai thị, thiểu sản gai thị,... Tỷ lệ nhóm bệnh liên quan thần kinh thị giác ở trẻ em và người lớn không khác nhau.

Nhóm bệnh lý do giác mạc chiếm tỷ lệ nhỏ $5.4 \%$, thường gặp các nguyên nhân sau: sẹo đục giác mạc, thoái hóa giác mạc, củng mạc hóa

giác mạc, loạn dưỡng giác mạc...

Nhóm bệnh glôcôm gây khiếm thị thực tế không hiếm gặp nhưng số lượng bệnh nhân bị bệnh này trong nghiên cứu của chúng tôi ít có thể do các bác sỹ chuyên khoa glôcôm chưa thực sự quan tâm để chuyển tuyến bệnh nhân. Ngoài ra có thể do bênh nhân đến khám trong giai đoạn quá muộn, đã mất chức năng thị giác.

\section{KẾT LUẬN}

Nguyên nhân gây khiếm thị ở người Việt nam đứng thứ nhất là bệnh lý võng mạc, đứng thứ hai là bệnh lý thể thửy tinh và đứng thứ ba là tật khúc xạ.

\section{TÀI LIÊU THAM KHẢO}

1. Chotikavanich $S$, Chanvarapha $N$, Loket $S$, Yingyong R, Dongngam $S$, Nujoi $\mathbf{W}$, Sangsre

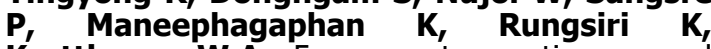
Krutthong W.A 5-year retrospective record review of hospital-based low-vision rehabilitation in Thailand. Clin Optom (Auckl). 2018; 10:41-50.

2. Congdon $\mathbf{N}$, O'Colmain B, Klaver $\mathrm{CC}_{\text {, }}$ et al.; Eye Diseases Prevalence Research Group. Causes and prevalence of visual impairment among adults in the United States. Arch Ophthalmol. 2004; 122(4):477-485.

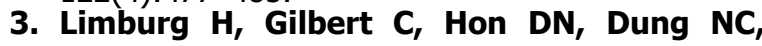


Hoang TH. Prevalence and causes of blindness in children in Vietnam. Ophthalmology. 2012 Feb; 119(2):355-61.

4. Muñoz B, West SK, Rubin GS, et al. Causes of blindness and visual impairment in a population of older Americans: the Salisbury Eye Evaluation Study. Arch Ophthalmol. 2000; 118(6):819-825.

5. Ngguê̂n Thị Thu Hiền, Nguyển Xuân Hiệp. ứng dụng phương pháp phuc hồi chức năng thị giác trên những người khiếm thị trưởng thành. Tạp chí Y học Việt nam. 2014; 417: 85-88.

6. Sapkota K, Kim DH. Causes of low vision and major low-vision devices prescribed in the lowvision clinic of Nepal Eye Hospital, Nepal. Anim Cells Syst (Seoul). 2017; 21(3):147-151.

7. Tôn Thị Kim Thanh, Nguyễn Thị Thu Hiền. Nghiên cứu ứng dụng môt sô dung cu trợ thi trên trẻ khiếm thị. Tạp chí nhãn khoa Việt nam. 2007; 9:45-54.

8. Vijaya $L$, George $R$, Asokan $R$, Velumuri $L$, Ramesh SV. Prevalence and causes of low vision and blindness in an urban population: The Chennai Glaucoma Study. Indian J Ophthalmol. 2014; 62(4):477-481.

\section{ĐĂC ĐIỂM CÂN LÂM SÀNG CỦA BÊ̂NH NHÂN PHẪU THUẬT SỎI TIẾT NIỆU TẠI BỆNH VIỆN ĐA KHOA ĐỨC GIANG}

\section{TÓM TẮT}

Mục tiêu: Mô tả đặc điểm cận lâm sàng của nhóm bênh nhhân sỏi tiết niêuu phải phấu thuật từ đó đưa một sổ kiến nghị về chỉ định xét nghiệm vi sinh. Phương pháp: nghiên cứu hồi cứu 56 bệnh nhân phẫu thuât sỏi tiết niệu tại bệnh viện đa khoa Đức Giang có xét nghiệm nuôi cấy tìm vi sinh vật từ tháng 9/2019 đến tháng 9/2020. Kết quả: Trong 56 bệnh nhân phấu thuật sỏi tiết niệu thì có $44,6 \%$ bênh nhân có tăng bạch cầu trong máu ngoại vi. Có $71,4 \%$ bệnh nhân có giãn đài bể thận. Có 54 bệnh nhân được nuôi cấy nước tiểu thì có $11,1 \%$ bênh nhân được xác định là dương tính (Escherichia Coli, Acinetobacter Baumannii, Klebsiella Pneumoniae, staphylococcus capitis). Có 13 bệnh nhân được cấy máu chiếm 23,2\% trong đó dương tính có 5 ca (Escherichia Coli, Staphylococcus saprophyticus, Candida albicans). Kết luận: Tỷ lệ nuôi cây phát hiên vi sinh vật là rất thấp nền đối với nhóm bệnh nhân sỏi tiết niệu phải phẫu thuật thì không nhất thiết phải làm xét nghiệm nuôi cấy thường quy. niệu

Tư khóa: Phẫu thuật sỏi tiết niệu, vi sinh vật tiết

\section{SUMMARY}

SUBCLINICAL CHARACTERISTICS OF PATIENS WITH URINARY STONE SURGERY AT DUC GIANG GENERAL HOSPITAL

Objective: to characterize some subclinical features of urinary stone patients requiring surgery, thereby giving some recommendations for microbiological testing. Method: Retrospective study of 56 urinary stone surgery patients at Duc Giang General Hospital with microbiological culture tests from September 2019 to September 2020. Result: In 56 patients with urinary stone surgery, $44.6 \%$ of patients had leukocytosis in peripheral blood.

${ }^{1}$ Bệnh viện đa khoa Đức Giang

Chịu trách nhiệm chính: Đố Minh Trí

Email: dominhtri37@yahoo.com.vn

Ngày nhận bài: 15.12.2020

Ngày phản biên khoa hoc: 25.01.2021

Ngày duyệt bài: 9.2.2021
Percentage of patients with pyeloderma was $71.4 \%$. In 54 patients with urine sample, $11.1 \%$ of the patients were confirmed positive (including Escherichia Coli, Acinetobacter Baumannii, Klebsiella Pneumoniae, staphylococcus capitis). Five patients were postive blood samples among $23.2 \%$ did microorganism culture ((Escherichia Coli, Staphylococcus saprophyticus, Candida albicans). Conclusion: The incidence of culture for detection of microorganisms was very low, so it is not necessary to do routine culture tests for urinary stone patients.

\section{I. ĐẶT VẤN ĐỀ}

Sỏi tiết niệu là chất khoáng nằm trong hệ tiết niệu, theo báo cáo gần đây của 7 quốc gia thì tỷ lệ hiện mắc sỏi tiết niệu là $7-14,8 \%$, và ở hầu hết các quốc gia [1]. S̉oi hay kết hợp với nhiễm trùng tiết niệu do gây tắc nghẽn đường bài tiết vi khuẩn sẽ ứ đọng, tập trung và từ đó có thể gây viêm, nhiễm khuẩn tại chố ngược dòng lên phía trên [2]. Ngược lại nhiễm trùng tiết niệu cũng làm bệnh nhân dễ hình thành sỏi [3]. Nhiểm trùng đặc hiệu do vi khuẩn đặc biệt gây nên như lao, lậu, nấm ... Nhiễm trùng không đặc hiệu do vi khuẩn gram (-) hay gram (+) [2]. Cẩu hỏi đặt ra là có cần thiết phải làm xét nghiệm vi sinh trong các bệnh nhân sỏi tiết niệu phải phẫu thuật hay không?. Để xác định được vi khuẩn thì bệnh viện phải có phòng xét nghiệm vi sinh, nuôi cẩy được vi khuẩn và thực hiện được kỹ thuật kháng sinh đồ. Trang bị này không phải bệnh viện nào cũng có.

\section{II. ĐỐl TƯỢNG VÀ PHƯƠNG PHÁP NGHIÊN CỨU}

2.1. Đối tượng nghiên cứu: Tổng số 56 bệnh nhân được phầu thuật sỏi tiết niệu tại bệnh viện đa khoa Đức Giang có xét nghiệm nuôi cấy máu hoặc nước tiểu tìm vi sinh vật trước mổ hoặc trong mổ.

2.2. Phương pháp nghiên cứu 